\title{
Periferik Fasiyal Paralizi ile Kliniğimize Başvuran Hastaların Analizi
}

\section{Analysis of Patients Applied to Our Clinic With Peripheral Facial Paralysis}

\author{
İsmail iYNEN ${ }^{1}(\mathbb{D})$, Mustafa ÇOBAN ${ }^{1}(\mathbb{D})$ Ali AKBAŞ $^{1}(\mathbb{D})$, Müslüm AYRAL ${ }^{1}$
}

${ }^{1}$ Harran Üniversitesi Tıp Fakültesi Kulak Burun Boğaz Hastalıkları Anabilim Dalı, Şanlıurfa/TÜRKiYE

Öz.

Amaç: Periferik Fasiyal Paralizi ile kliniğimize başvuran hastalarının; etyolojik, tedavi sonrası düzelme oranları ve eşlik eden komorbit hastalıklarla ilişkisini analiz etmeyi amaçladık.

Materyal ve Metod: Bu çalışma Harran Üniversitesi Kulak Burun Boğaz hastalıkları kliniğine yüzde asimetri, gözde kapanmama, yüzde uyuşukluk vb. şikayetler ile başvuran hastaların dosyaları incelenerek yapıldı. Toplam 300 hastanın dosyaları retrospektif olarak incelendi. Tüm hastaların dosyalarından; muayene bulguları, eşlik eden komorbit hastalıkları, tedavi öncesi ve sonrası House-Brakcman evrelemesi ve etyolojileri kayıt edildi. Çalışmaya son 1 ay içinde gelişen periferik fasiyal paralizili hastalar dahil edildi. 1 aydan daha uzun süre gelişen fasiyal parilizili hastalar, kontrollere düzenli devam etmeyen hastalar, santral fasiyal paralizi hastalar çalışma dışı bırakııldı.

Bulgular: Toplam 261 hasta çalışmaya dahil edildi. Hastaların 124'ü kadın(\%47,5) ve 137'isi erkek $(\% 52,5)$ idi. Hastaların arasında en küçük yaş 6 ay olup en büyük yaş ise 86 idi. Hastaların yaş ortalaması 28,2 idi. Hastalara eşlik eden komorbid hastalığı olan hasta sayısı $61(\% 33,4)$ idi. Bunlardan en sık \%19,2(n:50) ile Diabetes Mellitus daha sonra $\% 3,1(n: 8)$ ile Hipertansiyon ve $\% 1,1(n: 3)$ ile diğer grup olarak sınıflandırdığımız hastalıklar var idi. Hastaların etyolojik sonuçlarına baktığımızda en sık neden \%93,1(n:243) ile Bell Palsy daha sonra sıra ile \%3,1(n:8) akut otit, \%1,5(n:4) Rumsay Hunt Sendromu, \%1,5(n:4) travma ve \%0,8(n:2) ile iatrojenik olarak görüldü. Hastalarımızın House-Brackman evrelemesine göre en sık başvuru evresi $\% 46,7(n: 122)$ grade 3 idi. Daha sonra $\% 37,9(n: 99)$ ile grade 4, $\% 6,5(n: 17)$ grade 2 ve $\% 5,0(n: 13)$ grade 5 idi. Tedavi sonrası en sık olan House-Brackman evrelemesine göre grade ise $\% 47,9(n: 127)$ grade 2 idi. Daha sonra \%39,8(n:104) ile grade 1 idi.

Sonuç: Periferik fasiyal paralizi tedaviye erken başlama ve komorbid hastalık eşlik etmeyen kişilerde daha iyi progresyon göstermektedir. Diyabetes Mellitus periferik fasiyal paralizi progresyonunu en çok etkileyen kronik hastalıktır.

Anahtar Kelimeler: Yüz felci, Diyabetes Mellitus, House Brackmann

Abstract

Background: We aimed to analyze the etiologic and post-treatment recovery rates of patients with peripheral facial paralysis and their association with comorbid diseases.

Materials and Methods: This study was applied to Harran University Ear Nose and Throat Diseases Clinic with facial asymmetry, eye closure, facial numbness, etc. The files of the patients who applied with complaints were examined. The files of a total of 300 patients were reviewed retrospectively. From the files of all patients; Examination findings, accompanying comorbid diseases, House-Brakcman staging and etiologies before and after treatment were recorded. Patients with peripheral facial paralysis developed within the last 1 month were included in the study. Patients with facial parylysis that developed for more than 1 month, patients who did not attend the controls regularly, and patients with central facial paralysis were excluded from the study.

Results: A total of 261 patients were included in the study. 124 of the patients were female (47.5\%) and 137 were male (52.5\%). The youngest age among the patients was 6 months, and the oldest age was 86 . The average age of the patients was 28.2 . The number of patients with comorbid disease was $61(33.4 \%)$. The most common of these were Diabetes Mellitus with 19.2\% (n: 50), then Hypertension with 3.1\% (n: 8 ) and diseases that we classified as the other group with $1.1 \%(n: 3)$. When we look at the etiological results of the patients, the most common cause was Bell Palsy with $93.1 \%$ ( $n: 243)$ followed by $3.1 \%$ ( $n: 8)$ acute otitis, $1.5 \%(n: 4)$ Rumsay Hunt Syndrome, $1 \%$. Was iatrogenic, with $5(n: 4)$ trauma and $0.8 \%(n: 2)$. According to House-Brackman staging of our patients, the most common presentation stage was $46.7 \%$ (n: 122) grade 3. Then it was grade 4 with $37.9 \%(n: 99)$, grade 2 with $6.5 \%(n: 17)$ and grade 5 with $5.0 \%$ (n: 13$)$. Grade 2 was $47.9 \%$ ( $\mathrm{n}: 127$ ) according to House-Brackman staging, which was the most common after treatment. It was then grade 1 with $39.8 \%$ (n: 104).

Conclusions: Peripheralfacialparalysisshowsbetterprogression in patientswithoutearlyonset of treatmentandcomorbiddisease. DiabetesMellitus is themostcommonchronicdiseaseaffectingtheprogression of peripheralfacialparalysis.

Keywords: Facial paralysis, Diabetes Mellitus, House Brackmann

\section{Sorumlu Yazar / Corresponding Author}

Dr. İsmail IYYNEN

Harran Üniversitesi Tıp Fakültesi Kulak

Burun Boğaz Hastalıkları Anabilim Dalı, Şanlıurfa/TÜRKIYE

E-mail: iiynen@hotmail.com

Geliş tarihi / Received: 19.01.2020

Kabul tarihi / Accepted: 04.10.2021

DOI: 10.35440/hutfd.676073

16.11.2019 tarihinde 41.Türk KBB-BBC Ulusal Kongresi'n de sözlü sunulmuştur. 


\section{Giriş}

Periferik fasiyal paralizi (PFP), 7. kranial sinirin bası veya kesilmesi sonucu, yüz kaslarının kısmi veya tamamen felce neden olması ile kendini gösteren bir hastalıktır. Periferik yüz felcli bir hasta, üst ve alt yüz kaslarının tutulmasına neden olur ve yüz kaslarının zayıflı̆̆ı, yüz ifadesi kaybı, tat ve kornea duyumların kaybı ile görme sorunlarına neden olabilir (1). Periferik ve merkezi fasiyal sinir felci arasında ayrım yapmak için, hekim hastanın gülümsemesini ve her iki gözünü kapatıp kapanma kabiliyetini değerlendirerek yapabilir. Hastanın istirahat halindeki yüzünün asimetrisi veya maksimum çabasına rağmen hastanın gözlerini tamamen kapatmaması vb. durumlar ağır PFP'nin belirtileridir.

Her ne kadar birçok vaka idiopatik olsa da bir kısmı tanımlanabilir sebeplerle ilişkilidir. Nedeni ne olursa olsun, hastaların\% 85'i kısmi olarak işlevi geri kazanmakta, \% 70'inden fazlası tam iyileşmeyi başarmaktadır. En sık Bell Paralizi (BP) olarak isimlendirilen hastalık aynı zamanda idiyopatik yüz felci olarak da bilinir. Diğer nedenler arasında; doğuştan gelen fasiyal paralizi, enfeksiyonlar (akut ve kronik otitis media), travma, sendromlar, tümör, kronik sistemik hastalıklar ve metabolik bozukluklar bulunur.

Tedavisi kesin olmamakla beraber, steroid ve kombine tedaviler ile başarı oranı \%90 seviyesine çıkar. Spontan iyileşme oranı ise \%80 civarındadır (2).

Bu çalışmada kliniğimizde PFP tanısı konulan hastaların dosyalarından; demografik özellikleri, etyolojileri, eşlik eden hastalıklar, iyileşme oranları, verilen tedavilerin başarı oranlarını incelemeyi amaçladık.

\section{Materyal ve Metod}

Bu çalışma Harran Üniversitesi Kulak Burun Boğaz hastalıkları kliniğine Ocak 2015-Ağustos 2019 tarihleri arasında PFP tanısı ile başvuran hastaların dosyaları incelenerek yapılmıştır. Çalışma için Harran Üniversitesi Tıp Fakültesi Etik Kurulundan etik onam alınmıştır (Tarih; 09/09/2019 karar no:19/10/21). Çalışmaya dahil edilen 200 hasta ayaktan takip edilirken;100 hasta yatış yapılarak tedavisi yapılan hastalardan seçilmiştir. Hastaların fasiyal sinir disfonksiyonunun derecesi, House-Brackmann Fasiyal Sinir Sınıflandırma Ölçeğine (HBS) göre değerlendirildi (Tablo 1) (3).

Hastaların dosyalarından; yaş, cinsiyet, etyoloji, tedavi yöntemleri ve sonuçları incelendi. Çalışmaya son 1 ay içinde gelişen periferik fasiyal paralizili hastalar dahil edildi. 1 aydan daha uzun süre gelişen fasiyal parilizili hastalar, kontrollere düzenli devam etmeyen hastalar, santral fasiyal paralizi hastalar çalışma dışı bırakıldı.

Tüm hastalara temel tedavi olarak prednol $1 \mathrm{mg} / \mathrm{kg}$ başlandı. Bu tedavi ilk 72 saatte başlanmış olup 3 gün aralıklarla azaltılarak devam edildi ve 10 güne tamamlandı. Hastaların tedavisi etyolojisi saptandıktan sonra prednol tedavisine ek olarak gerektiğinde antibiyoterapi, antiviral tedavi, cerrahi operasyon yapıldı. Yapay gözyaşı ve yüz eg- zersizleri de göz doktoru ve fizyoterapist tarafından verilen önerilere göre yapıldı.

Tablo 1. House-Breckman Sınıflama Sistemi

\begin{tabular}{|c|c|c|}
\hline HASAR DERECESI & GRADE & TANIMLAMA \\
\hline Normal & 1 & $\begin{array}{l}\text { Bütün alanlarda normal simetrik fonksi- } \\
\text { yon }\end{array}$ \\
\hline Hafif disfonksiyon & 2 & $\begin{array}{l}\text { Sadece yakın gözlemle farkedilebilen } \\
\text { Minimal eforla tam kapananilir } \\
\text { Gülümserken hafif asimetri var } \\
\text { Sinkinezi var, kontraktür ve ya spazm } \\
\text { yok. }\end{array}$ \\
\hline $\begin{array}{l}\text { Orta derece disfonksi- } \\
\text { yon }\end{array}$ & 3 & $\begin{array}{l}\text { Belirgin göçsüzlük var, şekil bozukluğu } \\
\text { yok } \\
\text { Kaşını kaldıramaz } \\
\text { Gözünü tam kapatabilir fakat maksimal } \\
\text { eforla göçlü ancak asimetrik ağız hare- } \\
\text { keti } \\
\text { Belirgin fakat şekli bozmayan sinkinezi } \\
\text { kitle hareketi ve ya spazm }\end{array}$ \\
\hline $\begin{array}{l}\text { Orta-ileri derece dis- } \\
\text { fonksiyon }\end{array}$ & 4 & $\begin{array}{l}\text { Aşikar şekil bozucu göçsüzlük } \\
\text { Kaşı kaldıramama } \\
\text { Gözü kapatamama, maksimal eforla } \\
\text { ağızda asimetri } \\
\text { Ciddi sinkinezi , kitle hareketi , spazm }\end{array}$ \\
\hline Ciddi disfonksiyon & 5 & $\begin{array}{l}\text { Hareket zorlukla anlaşılır } \\
\text { Gözü tam kapatamama } \\
\text { Ağız köşesinde hafif hareket } \\
\text { Sinkinezi , kontraktür ve ya spazm ge- } \\
\text { nellikle yok }\end{array}$ \\
\hline Total paralizi & 6 & $\begin{array}{l}\text { Hareket yok } \\
\text { Tonus kaybı var } \\
\text { Sinkinezi, kontraktür ve ya spazm yok }\end{array}$ \\
\hline
\end{tabular}

\section{Bulgular}

Hastaların dosyalarından; yaş, cinsiyet, klinik özellikleri, tedavi öncesi ve tedavi sonrası House-Brakcman evreleri, etyolojik nedenler ve komorbid hastalıkları analiz edildi. Toplam 300 olan hastadan 261 hasta çalışmaya dahil edildi. 39 hasta takiplerini eksik yaptığı için çalışmaya alınmadı. Hastaların 124'ü kadın(\%47,5) ve 137 'isi erkek idi(\%52,5). Hastaların arasında en küçük yaş 6 ay olup en büyük yaş ise 86 idi. Hastaların yaş ortalaması 28,2 idi. Hastalara eşlik eden komorbid hastalığı olan hasta sayısı $61(\% 33,4)$ idi. Bunlardan en sık \%19,2(n:50) ile Diabetes Mellitus (DM) daha sonra \%3,1(n:8) ile Hipertansiyon (HT) ve $\% 1,1(n: 3)$ ile diğer grup olarak sınıflandırdığımız hastaIıklar var idi. Komorbid hastalıkları olan hastalar klinikte yatışları yapılarak tedavi edildi. Hastaların etyolojik sonuçlarına baktığımızda en sık neden \%93,1(n:243) ile Bell Paralizi daha sonra sıra ile \%3,1(n:8) akut otit, \%1,5(n:4) Rumsay Hunt Sendromu, \%1,5(n:4) travma ve \%0,8(n:2) ile iatrojenik olarak görüldü. İatrojenik hastalarımız mastoidektomi cerrahisi sonrası olan hastalar idi. Hastalarımızın House-Brackman evrelemesine göre en sık başvuru evresi $\% 46,7(n: 122)$ grade 3 idi. Daha sonra \%37,9(n:99) ile grade $4, \% 6,5(\mathrm{n}: 17)$ grade 2 ve $\% 5,0$ (n:13) grade 5 idi. Tedavi sonrası House-Brackman evrelemesine göre en sık $\% 47,9(n: 127)$ ile grade 2 idi. Daha sonra \%39,8(n:104) ile grade 1 idi (Tablo 2 ). 
Tablo 2. Hastaların Demoğrafik Özellikleri

\begin{tabular}{lc}
\hline Yaş & ( Ortalama) 28,2 \\
\hline Cinsiyet & \\
Erkek & $137(52,5)$ \\
Kadın & $124(47,5)$ \\
\hline Etyoloji & $243(93,1)$ \\
Bell Paralizi & $8(3,1)$ \\
Akut otit & $4(1,5)$ \\
Rumsay Hunt Sendromu & $4(1,5)$ \\
Travma & $2(0,8)$ \\
latrojenik & \\
\hline Komorbid hastalıklar & $50(19,2)$ \\
DM & $8(3,1)$ \\
HT & $3(1,1)$ \\
Diğer & $200(76,6)$ \\
Yok & \\
\hline HBE başvuru evresi & $1(0,4)$ \\
Grade 1 & $17(6,5)$ \\
Grade 2 & $122(46,7)$ \\
Grade 3 & $99(37,9)$ \\
Grade 4 & $13(5,0)$ \\
Grade 5 & $0(0)$ \\
Grade 6 &
\end{tabular}

Hastaların House-Brackman evrelemesine göre başvuru evreleri ile tedavi sonrası evreleri arasında anlamlı düzeyde iyileşme görüldü. En sık görülen tedavi öncesi grade 3 evresi tedavi sonrası grade 1 ve 2'ye geriledi. Hastaların tedavi öncesi ve sonrası House-Brackman evrelemesi Tablo 3' de gösterilmiştir.

Komorbid hastalığı olan hastalarımızın özellikle DM'u olan hastaların başvuru evreleri en çok grade 4 iken DM'u olmayan hastalarımızın grade 3 idi. Hastaların tedavi sonrası iyileşme oranlarına komorbid hastalıkların olması anlamlı bir fark oluşturdu. DM'u olan hastalarımız tedavi sonrası en çok grade 2'ye geriledi. Tablo 3'de komorbid hastalıkların eşlik ettiği hastalarda tedavi başarısına olumsuz etkisi olduğu gösterilmiştir.

Tablo 3. Komorbid hastaların tedavi öncesi ve sonrası evrelerinin karşılaştırması

\begin{tabular}{|c|c|c|c|c|c|c|c|}
\hline \multirow[t]{2}{*}{ DM } & & & \multicolumn{4}{|c|}{ Tedavi sonrası evre } & \multirow[b]{2}{*}{ Total } \\
\hline & & & Grade 1 & Grade 2 & Grade 3 & Grade 4 & \\
\hline \multirow{5}{*}{$\begin{array}{l}\text { DM } \\
\text { VAR }\end{array}$} & \multirow{4}{*}{$\begin{array}{c}\text { Tedavi } \\
\text { öncesi } \\
\text { evre }\end{array}$} & Grade 2 & 0 & 1 & 0 & 0 & 1 \\
\hline & & Grade 3 & 5 & 5 & 1 & 0 & 11 \\
\hline & & Grade 4 & 2 & 13 & 12 & 0 & 27 \\
\hline & & Grade 5 & 0 & 5 & 5 & 1 & 11 \\
\hline & \multicolumn{2}{|l|}{ Total } & 7 & 24 & 18 & 1 & 50 \\
\hline \multirow{6}{*}{$\begin{array}{l}\text { DM } \\
\text { YOK }\end{array}$} & \multirow{5}{*}{$\begin{array}{c}\text { Tedavi } \\
\text { öncesi } \\
\text { evre }\end{array}$} & Grade 1 & 1 & 0 & 0 & & 1 \\
\hline & & Grade 2 & 10 & 6 & 0 & & 16 \\
\hline & & Grade3 & 47 & 59 & 0 & & 106 \\
\hline & & Grade4 & 33 & 33 & 3 & & 69 \\
\hline & & Grade5 & 0 & 0 & 2 & & 2 \\
\hline & \multicolumn{2}{|l|}{ Total } & 91 & 98 & 5 & & 194 \\
\hline \multirow{6}{*}{ Total } & \multirow{5}{*}{$\begin{array}{c}\text { Tedavi } \\
\text { öncesi } \\
\text { evre }\end{array}$} & Grade1 & 1 & 0 & 0 & 0 & 1 \\
\hline & & Grade2 & 10 & 7 & 0 & 0 & 17 \\
\hline & & Grade3 & 52 & 64 & 1 & 0 & 117 \\
\hline & & Grade4 & 35 & 46 & 15 & 0 & 96 \\
\hline & & Grade5 & 0 & 5 & 7 & 1 & 13 \\
\hline & \multicolumn{2}{|l|}{ Total } & 98 & 122 & 23 & 1 & 244 \\
\hline
\end{tabular}

\section{Tartışma}

Fasiyal sinir paralizileri birçok farklı nedene bağlı olarak görülebilir. Bu nedenler arasında; genetik faktörler, viral infeksiyona bağlı gelişen vasküler iskemi ve inflamasyon, otoimmun hastalıklar, temporal kemik fraktürleri, baş-boyun tümörleri, santral sinir sistemi lezyonları yer almaktadır. Ancak tüm bu bilinen nedenlere karşın fasiyal paralizilerin büyük çoğunluğu "idiopatik" (BP) olarak karşımıza çıkmaktadır (1). Çalışmamızda da literatüre uygun olarak en sık neden \%93,1 ile BP idi. Yapılan çalışmalarda yıllık 20-37.7 / 100.000 BP insidansı bildirmiştir (7). Hancı ve ark.'larının yaptığı çalışmada bu oran $\% 65,4$ olarak belirtmişlerdir (1). Psillas ve ark. ise \%88 olarak bildirmişlerdir (5). BP herhangi bir yaşta ortaya çıkabilir, ancak daha çok $10-40$ ya da $15-45$ yaşları arasında görülür $(6,7)$. Bizim çaIışmamızda yaş ortalaması 28,2 idi. BP'nin prognozunu etkileyen bir takım faktörler mevcuttur bunlar; yaş, cinsiyet, $\mathrm{HT}$, hiperkolesterolemi ve DM'u içermektedir (10). Biz de çalışmamızda bunun ilişkisini irdelemeye çalıştık. Elicora ve ark. ları diyabet ve iyileşme eksikliği arasında bir ilişki olduğunu tespit etmiştir. Pediatrik hastalarda fasiyal paralizinin nedenler arasında Bell Paralizi, Herpes Zoster Oticus, otitis media, travma, doğum yaralanması, lösemi ve yanıklar bulunmaktadır $(4,8,9)$. Bizim çalışmamızda literatüre uygun olarak çocuk grubu hastalarımızda periferik fasiyal paralizi etyolojisinde; akut otitis media, Rumsay Hunt Sendromu ve travma ön planda olduğu tespit edildi. Yapılan bazı çalışmalarda akut otitis media, periferik fasiyal sinir paralizisinin en sık nedenlerinden biri olarak rapor edilmiştir $(5,6)$. Ancak akut otitis media prevalansı antibiyotik tedavisi ve erken tedavi nedeniyle azaldığından fasiyal sinir paralizi prevalansı da azalmıştır (8). Bizim çaıışmamızda bu yargıya uygun olarak genel çalışma içinde akut otit etyolojisi düşük olarak görüldü.

Ramsay-Hunt Sendromu tanısı kulak ağrısı, yüz felci ve dış kulak kanalının patogonomik veziküllerinin varlığında klinik olarak konulabilir. Bizim de çakışmamı literatüre uyumlu olarak Rumsay-Hunt tanısı konulan hastaların hepsinde dış kulak yolunda vezikülleri mevcuttu. RamsayHunt Sendromlu hastaların prognozu kötü olduğundan antiviral tedavi standart tedaviye muhakkak eklenmelidir (7). Çalışmamızda Rumsay Hunt Sendromu tanısı konulan tüm hastalara steroid tedavisine ek olarak antiviral tedavi eklendi.

\section{Sonuç}

Komorbid hastalıkla birlikte periferik fasiyal paralizisi olan hastaların daha kötü progresyon gösterdiği ancak periferik fasiyal paralizi olan hastaların tedaviye erken başvurması ve komorbid hastalıkların eşlik etmemesi durumunda progresyonun ve tedaviye cevabın daha iyi olduğu tespit edilmiştir. 
Etik onam: Çalışma için Harran Üniversitesi Tıp Fakültesi Etik Kurulundan etik onam alınmıştır (Tarih; 09/09/2019 karar no:19/10/21).

\section{Yazar Katkıları:}

Konsept: i.i.

Literatür Tarama: i.i., M.Ç.

Tasarım: i.i.

Veri toplama: M.C., A.A., M.A.

Analiz ve yorum: M.Ç., i.i.

Makale yazımı: i.i., M.Ç.

Eleştirel incelenmesi: i.i., M.Ç., M.A.

Çıkar Çatışması: Herhangi bir çıkar çatışmamız bulunmamaktadir.

Finansal Destek: Araştırma kapsamında herhangi bir kurum ya da kuruluştan finansal destek sağlanmamıştır.

\section{Kaynaklar}

1. Hanci F, Türay S, Bayraktar Z, Kabakuş N. Childhood Facial Palsy: Etiologic Factors and Clinical Findings, an Observational Retrospective Study. Journal of Child Neurology. 2019;34(14):907-912

2. Garro A, Nigrovic LE. Managing Peripheral Facial Palsy, Annals of Emergency Medicine. 2018;71(5):618-24

3. Silva MFF, Peres SV, Lazarini PR, Cunha MC. Evaluation of the sensitivity of the Psychosocial Scale of Facial Appearance in peripheral facial paralysis. Codas. 2018 Nov 29;30(6):e20180072.

4. Tabarki B. Prise en charge de la paralysie faciale périphérique chez l'enfant [Management of peripheral facial nerve palsy in children]. Arch Pediatr. 2014;21(10):1145-8

5. Psillas $\mathrm{G}$, Antoniades $\mathrm{E}$, leridou $\mathrm{F}$, Constantinidis J. Facial nerve palsy in children: A retrospective study of $124 \mathrm{ca}-$ ses. J Paediatr Child Health. 2019 Mar;55(3):299-304.

6. Özkale Y, Erol İ, Saygı S, Yılmaz i. Overview of pediatric peripheral facial nerve paralysis: analysis of 40 patients. J Child Neurol. 2015;30(2):193-9.

7. Zimmermann J, Jesse S, Kassubek J, Pinkhardt E, Ludolph AC. Differential diagnosis of peripheral facial nerve palsy: a retrospective clinical, MRI and CSF-based study. J Neurol. 2019;266(10):2488-2494

8. Cha HE, Baek MK, Yoon JH, Yoon BK, Kim MJ, Lee JH. Clinical features and management of facial nerve paralysis in children: analysis of 24 cases. J Laryngol Otol. 2010;124(4):402-6.

9. Jenke AC, Stoek LM, Zilbauer M, Wirth S, Borusiak P. Facial palsy: etiology, outcome and management in children. Eur J Paediatr Neurol. 2011;15(3):209-13

10. Şevik Eliçora S, Erdem D. Does Type 2 Diabetes Mellitus Affect the Healing of Bell's Palsy in Adults? Can J Diabetes. 2018;42(4):433-436. 